\title{
Spatiotemporal Patterns in the Airborne Dispersal of Spinach Downy Mildew
}

\author{
R. A. Choudhury, S. T. Koike, A. D. Fox, A. Anchieta, K. V. Subbarao, S. J. Klosterman, and N. McRoberts
}

First, fifth, and seventh authors: Department of Plant Pathology, University of California, Davis 95616; second author: University of California Cooperative Extension, 1432 Abbott St., Salinas 93901; third author: Fox Weather, LLC, Fortuna, 95540; and fourth and sixth authors: United States Department of Agriculture-Agricultural Research Service, 1636 E. Alisal St., Salinas, CA 93905.

Accepted for publication 25 July 2016.

\begin{abstract}
Downy mildew is the most devastating disease threatening sustainable spinach production, particularly in the organic sector. The disease is caused by the biotrophic oomycete pathogen Peronospora effusa, and the disease results in yellow lesions that render the crop unmarketable. In this study, the levels of DNA from airborne spores of $P$. effusa were assessed near a field of susceptible plants in Salinas, CA during the winter months of 2013-14 and 2014/15 using rotating-arm impaction spore-trap samplers that were assessed with a species-specific quantitative polymerase chain reaction (qPCR) assay. Low levels of P. effusa DNA were detectable from December through February in both winters but increased during January in both years, in correlation with observed disease incidence; sharp peaks in $P$. effusa DNA detection were associated with the onset of disease incidence. The incidence of downy mildew in the susceptible field displayed

logistic-like dynamics but with considerable interseason variation. Analysis of the area under the disease progress curves suggested that the 2013-14 epidemic was significantly more severe than the 2014-15 epidemic. Spatial analyses indicated that disease incidence was dependent within an average range of $5.6 \mathrm{~m}$, approximately equivalent to the width of three planted beds in a typical production field. The spatial distribution of spores captured during an active epidemic most closely fit a power-law distribution but could also be fit with an exponential distribution. These studies revealed two important results in the epidemiology of spinach downy mildew in California. First, they demonstrated the potential of impaction spore-trap samplers linked with a qPCR assay for indicating periods of high disease risk, as well as the detection of long-distance dispersal of $P$. effusa spores. Second, at the scale of individual crops, a high degree of spatial aggregation in disease incidence was revealed.
\end{abstract}

Spinach is an economically important leafy salad vegetable and has been increasingly consumed as an important part of a healthy diet (Correll et al. 2011). Increasing demand for fresh-market spinach has driven changes in production in the United States, such as the use of wider beds and denser plantings (Koike et al. 2011). In the United States, most spring and summer spinach production occurs in the Salinas Valley of California, whereas fall and winter production occurs in the Imperial and Yuma Valleys of California and Arizona, respectively. Together, these regions account for over $90 \%$ of the spinach produced in the United States annually (USDANASS 2015). The seasonal shift in production is driven by the optimal growth conditions of the crop and the year-long demand for fresh-market spinach. There is little to no commercial freshmarket spinach production in these regions during their respective off-seasons. In all regions where spinach is grown, increasing production has coincided with an increase in downy mildew (Correll et al. 2011).

Downy mildew is a threat to spinach worldwide (Correll et al. 2011) and is caused by the obligate oomycete biotroph Peronospora effusa (Grev.) Rabenh (previously P. farinosa f. sp. spinaciae) (Choi

Corresponding authors: S. J. Klosterman; E-mail address: steve.klosterman@ars.usda.gov; and N. McRoberts; E-mail address: nmcroberts@ucdavis.edu

Mention of trade names or commercial products is solely for the purpose of providing specific information and does not imply recommendation or endorsement by the U.S. Department of Agriculture. USDA is an equal opportunity provider and employer.

*The $e$-Xtra logo stands for "electronic extra" and indicates that four supplementary figures are published online.

This article is in the public domain and not copyrightable. It may be freely reprinted with customary crediting of the source. The American Phytopathological Society, 2017. et al. 2007; Thines and Choi 2016). P. effusa is endemic to all spinach-growing regions, and co-occurs with many other closely related downy mildew species (Choi et al. 2007; Klosterman et al. 2014). Like these other oomycete species, $P$. effusa produces longterm survival structures known as oospores. Oospores of $P$. effusa are present on $16 \%$ of modern spinach seed lots and this may represent one route of long-distance transmission (Kunjeti et al. 2016), likely contributing to worldwide distribution.

Spinach downy mildew may be especially difficult to control under conditions in which plants are densely packed, with high moisture levels supplied by overhead irrigation, because the disease is favored by cool, moist conditions, and can spread rapidly through the production of airborne sporangia (Frinking and van der Stoel 1987). The symptoms of spinach downy mildew, characterized by leaf chlorosis and lesions, severely reduce acceptability of the fresh-market crop, especially for organic growers who cannot use synthetic pesticides for disease control (Feng et al. 2014).

Recent work has focused on monitoring airborne populations of $P$. effusa during the main growing season in the Salinas Valley using a quantitative polymerase chain reaction (qPCR) assay linked with an impaction spore-trap sampler (Klosterman et al. 2014). Little is known about how airborne inoculum levels of $P$. effusa fluctuate during the off-season in the Salinas Valley, when commercial spinach is only planted sparingly for processing. All obligate biotrophic pathogens need to survive host-free periods that often occur during winter in temperate climates. Overwintering strategies differ between obligate pathogens; some produce durable, dormant structures and others rely on green bridge crops to propagate and survive (Gadoury et al. 2012; McDonald and Linde 2002; Montarry et al. 2007; Spanu 2012). Though oospores of $P$. effusa have not been reported on spinach leaves in commercial fields of the Salinas Valley, there remains clear potential for bridging crops to contribute 
inoculum, as demonstrated by the detection of DNA of airborne P. effusa prior to the main growing season (Klosterman et al. 2014).

Cross-inoculation studies suggest that $P$. effusa only infects spinach plants and cannot infect other closely related cultivated plants such as beet and Swiss chard (Byford 1967; Klosterman et al. 2014). Phylogenetic analyses indicate that $P$. effusa is distinct from other Peronospora spp. (Choi et al. 2015); this host specificity would limit the ability of $P$. effusa to overwinter by reducing the number of viable hosts. Although it is difficult to fully exclude the possibility of infection on volunteer spinach plants, the relatively rapid progression of disease symptoms from infection to sporulation and decline suggests that this is unlikely (van den Bosch et al. 1988). Understanding how overwintering populations survive and fluctuate in levels may lead to more effective disease control strategies.

Without suitable alternative hosts in the absence of spinach crops, P. effusa populations are thought to decline. In other downy mildew systems, these host-free periods are sometimes characterized by local extirpation and recolonization events (LaMondia and Aylor 2001). Recolonization events can be mediated by asymptomatic infection of transplant seedlings, germination and infection of soil- or seed-borne oospores, movement of pathogen propagules on infested farm equipment, or long-distance dispersal (LDD) of airborne spores (Aylor 2003; Ojiambo and Holmes 2011). These LDD events have been hypothesized as the cause of disease outbreaks for several plant pathogens, as well as the possible intercontinental introduction of new pathogens (Aylor 2003; Brown and Hovmøller 2002). Environmental microbiologists have observed long-distance deposition of microbes and particulates at continental scales (Kellogg and Griffin 2006).

Dispersal events of plant pathogens often take place at multiple scales, expanding outward through the creation of new disease foci (Zadoks and van den Bosch 1994). As disease foci converge, the emerging disease front appears as an expanding wave on the landscape. Understanding how regional spore dispersal affects disease is critical for proper disease control. Monitoring airborne $P$. effusa levels during the off-season may reveal cryptic features of the pathogen's life cycle that may explain its capacity for rapid population increase during the host growing season.

Although several studies have shown how rapidly other closely related downy mildew species colonize and spread (Ojiambo and Holmes 2011; Stein et al. 1994; Wu et al. 2001), there are relatively few data on the spatiotemporal patterns of spinach downy mildew. This is especially true in regards to the situation with more modern production practices, which utilize high-density salad spinach plantings in wide beds. At the same time, although the agronomy of the crop has changed to suit fresh-market salad production, an increasing acreage has been planted, resulting in intensification both at the level of individual crops and across the main production regions (Koike et al. 2011). Without information on pathogen dispersal and disease intensity, it is difficult to predict how a single diseased field might affect disease within a region.

In this study, we used impaction spore-trap samplers and qPCR assays to monitor airborne $P$. effusa levels over two winter periods in the Salinas Valley. We also monitored the progress of disease incidence in nearby fields of susceptible spinach. The study had three goals: (i) to understand how airborne P. effusa levels vary over the winter months, when relatively little commercial spinach is grown; (ii) to understand LDD patterns of $P$. effusa spores; and (iii) to characterize the spatiotemporal patterns of disease progression in a field of susceptible spinach.

\section{MATERIALS AND METHODS}

Field site. Four 2-m beds of 'Viroflay' spinach were planted at the Hartnell College East Campus site in Salinas, CA on 25 November 2013 and maintained until 11 February 2014. The same site was planted again with Viroflay on 20 November 2014 and maintained until 6 February 2015 . Viroflay is universally susceptible to all races of spinach downy mildew (Feng et al. 2014). The fields were 37 by $10 \mathrm{~m}$ in area and the field sites were planted at a density of approximately 5 million seeds/ha. The sites were supplied with supplemental overhead irrigation twice each week in the absence of rain, mimicking conditions used by commercial growers.

Spore trapping and qPCR. Rotating-arm impaction spore-trap samplers (Falacy et al. 2007; Thiessen et al. 2016) were placed approximately $2 \mathrm{~m}$ from the edge at the four cardinal points around the susceptible spinach field in the Salinas Valley 2013-14 and 2014-15 winters. Spore-trap samplers operated continuously throughout the study period, and the 40-mm stainless steel, grease-coated spore-trap rods (316LSi stainless steel; Harris Products Group) were collected three times a week at intervals of 48,48 , and $72 \mathrm{~h}$ from late November to mid-February in both years. The rods were stored at $4{ }^{\circ} \mathrm{C}$ for 1 to 2 weeks until DNA extractions were performed. Remaining extracted samples were stored at $-80^{\circ} \mathrm{C}$.

DNA extractions from rods were carried out using a NucleoSpin Plant II kit (Machery-Nagel). The qPCR (TaqMan) assays were conducted with the single-nucleotide polymorphism-specific primers for $P$. effusa and $P$. schachtii, and results were expressed as copy number of $P$. effusa ribosomal DNA, as previously described (Klosterman et al. 2014).

Long-distance spore dispersal. Two field sites were used to study long-distance movement of $P$. effusa spores: a commercial spinach crop in Soledad, CA and the Salinas Valley field site described above. At the Soledad site, as reported previously (Klosterman et al. 2014), two spore traps were placed next to a commercial spinach field in Soledad, CA that had an active downy mildew outbreak from 13 March to 3 April 2013. One spore trap was placed at the north end and one approximately $750 \mathrm{~m}$ away, at the south end of the field, to address variation in spore capture caused by diurnal wind patterns. At the Salinas site, the LDD was examined in the 2013-14 winter, from 30 January to 11 February 2014. Spore trapping at Soledad 2013 and the Salinas 2013-14 epidemic was concurrent with other spore-trap samplings throughout the Salinas Valley, at five other locations roughly 15 to $20 \mathrm{~km}$ apart (Supplementary Fig. S1). Two traps were operated at each of the five locations. The spore-trap rods were collected three times per week at intervals of 48,48 , and $72 \mathrm{~h}$ and processed as described above. The Salinas 2014-15 field site was not included in the analysis of LDD because there were no other trapping efforts in the Salinas Valley during that period. Field scouting by R. A. Choudhury and discussions with local growers suggested that there were no other serious downy mildew epidemics occurring in the region during the study period of the Salinas 2013-14 and Soledad epidemics. The linear distance between spore-trap locations was calculated based on their GPS coordinates using the R v3.2.4 statistical programming language (R Core Team 2016) and the package geosphere v1.5-5 (Hijmans 2016).

Disease incidence rating. Disease incidence ratings at the Salinas 2013-14 and Salinas 2014-15 sites were conducted on a weekly basis, beginning when plants had four true leaves. In 2013-14, two adjacent $1-\mathrm{m}^{2}$ areas were marked out with flags on every bed, spaced evenly apart every $3.5 \mathrm{~m}$ along the bed (Supplementary Fig. S2A), with a total of 72 rating areas in the field per time point. In 2014-15, four adjacent $1-\mathrm{m}^{2}$ areas were marked out with flags on every bed, spaced evenly apart every $2.5 \mathrm{~m}$ along the bed (Supplementary Fig. S2B), with a total of 144 rating areas in the field per time point. These disease incidence areas were rated for presence or absence of visible downy mildew symptoms on individual leaves, and ratings were expressed as an estimate of the proportion of diseased leaves in the rated area. Ratings in both winters concluded when plants were fully mature and beginning to bolt, leading to senescence of diseased tissue.

Weather data. High-quality weather data for individual field sites were generated by Fox Weather, LLC using the MtnRT custom software described by Fox (2011). For the basic initial data, we used the North American Regional Reanalysis (NARR) obtained from the National Oceanic and Atmospheric Administration at 32-km grid spacing and 3-h time step. From the NARR data, we produced 
sequential nested weather research and forecasting (WRF) model runs (4-km grid) to provide input for MtnRT. Using MtnRT, running at a $1.5-\mathrm{km}$ grid, we produced a continuous record of hourly data, including wind direction and speed at 2 and $50 \mathrm{~m}$ above ground, and the other weather parameters mentioned above. The forecast point locations for the two winter periods included the following stations: 201 at $36.6245 \mathrm{~N}, 121.5393 \mathrm{~W}$, and 206 at $36.6701 \mathrm{~N}, 121.6047 \mathrm{~W}$. For February 2015, the NARR data were not available. Therefore, the WRF $12 \mathrm{~km}$ was used with forecast hours $\mathrm{t}+6$ to $\mathrm{t}+24$ from Fox Weather's operational WRF archive to produce data for the MtnRT simulations.

The MtnRT processing included the interpolation to 1-h increments for the surface weather data, including wind direction and speed (Mesinger et al. 2006). This included consideration of MtnRT's calculation of wind vector variations resulting from development of nocturnal inversions. Wind speed was calculated at a 2-m height above ground instead of the standard 10-m height. This was done to better represent wind speeds at the top of the canopy for spinach or lettuce crops. The calculation of wind speed at $2 \mathrm{~m}$ was based on a logarithmic relationship of wind speed versus distance above ground. A simplified version of the theoretical logarithmic relationship is $\mathrm{U} 2=\mathrm{U} 1[\ln (\mathrm{h} 2 / \mathrm{z} 0) / \ln (\mathrm{h} 1 / \mathrm{z} 0)]$, where $\mathrm{U} 2$ is wind speed to be calculated (in this case at $\mathrm{h} 2=2 \mathrm{~m}$ ), while $\mathrm{U} 1$ is the speed at the reference height (h1). The value of roughness length $\mathrm{z} 0$ for most purposes would be 0.1 to 0.2 for the environment that includes the field plot. For illustration, given a reference height of $50 \mathrm{~m}$ and speed U1 of $10 \mathrm{~m} / \mathrm{s}$, the $2-\mathrm{m}$ speed U2 would be close to $3 \mathrm{~m} / \mathrm{s}$ and $10-\mathrm{m}$ speed at $4.1 \mathrm{~m} / \mathrm{s}$. Our implementation for nearsurface wind profiles in MtnRT provides inputs to operational forecasts in many different types of terrain and roughness conditions. For this project, we used the standard logarithmic wind profile used in our operational version of MtnRT. All wind calculations are referenced for the areas outside of the plant canopy.

When necessary, supplemental weather data for the Salinas 2013-14 and Salinas 2014-15 winters were collected from the nearby Salinas California Irrigation Management Information System (CIMIS) weather station (Salinas South II, Station 214) and the Salinas Municipal Airport weather station. Weather data collected from the CIMIS station included hourly measurements of temperature, relative humidity, wind speed, and wind direction, and data collected from the airport station included hourly measurements of cloud coverage.

Spatial analysis of spore-trap data. The natural log of the P. effusa copy numbers from the Salinas 2013-14 epidemic and the Soledad epidemic and from spore traps throughout the Salinas Valley (discussed above in long-distance distribution) were plotted against both the natural log of the distances and the untransformed distances of the epidemic sites to the Salinas Valley traps. In total, the time series data from the Salinas 2013-14 and Soledad epidemics had 69 and 115 spore copy number measurements, respectively. A small constant $(=1)$ was added to the distance data before natural $\log$ transformation to prevent undefined results. These data were fitted using a linear regression, as described by Fitt et al. (1987).

An empirical bootstrapping procedure was used to determine whether a power-law or exponential dispersal distribution provided a better description of the observed spore dispersal data. The Salinas 2013-14 and Soledad epidemic datasets were resampled with replacement 10,000 times, with each resampled dataset for pathogen log DNA copy number fitted to the untransformed or logarithmic distances using linear regression. The Akaike information criterion (AIC) value for each fitted model was collected, and the AIC values for the untransformed and logarithmic distance models were compared using Welch's $t$ test. The AIC is a metric commonly used for model selection, and is a measure of the expected relative entropy between two sets of data: the predicted dataset and the actual dataset (McRoberts et al. 2011). The AIC balances the complexity of a model with its likelihood value for a set of data, allowing the tasks of model selection and parameter estimation to be combined in an objective manner (Forster and Sober 1994).
Because the AIC is a measure of divergence, superiority of one model over another is indicated by a lower overall AIC value for the superior model.

Temporal analysis of disease incidence data. Disease progress over time at the Salinas 2013-14 and Salinas 2014-15 sites was examined by modeling disease incidence data with a nonlinear regression to estimate the parameters of a logistic growth function (Sparks et al. 2008). In one widely used format, the standard logistic is defined by the equation $Y=K /\left[1+\beta^{(-r t)}\right]$, with $Y$ and $t$ representing the percent disease incidence and the number of days after the first disease rating, respectively. The coefficients $K, r$, and $\beta$ are the maximum disease level, rate parameter, and constant term (capturing the initial condition) of the model, respectively. The rate of change of disease level $Y$ at time $t$ was determined using the derivative $Y^{\prime}(t)=r Y(K-Y)$, allowing for an estimate of the daily rate of disease change.

The area under the disease progress curve (AUDPC) was calculated for each disease incidence rating area for the Salinas 2013-14 and 2014-15 epidemics. The AUDPC was estimated as the sum of the trapezes under the curve using the R package agricolae v1.2-3 (de Mendiburu 2015). The area approximates the total overall amount of disease in each winter season, and is commonly used to compare epidemics from different regions or time spans (Madden et al. 2007). The AUDPC of the disease rating areas from the 2013-14 and 2014-15 Salinas epidemics were compared using Welch's two-sample $t$ test.

Spatial analysis of disease incidence data. Spatial correlations between disease incidence rating areas at the Salinas 2013-14 and Salinas 2014-15 sites were determined by analyzing isotropic semivariograms using the $\mathrm{R}$ package CompRandFld v1.0.3-4 (Padoan and Bevilacqua 2015). Semivariograms measure the average variability between the points $z_{i}$ and $z_{i+h}$ lying $h$ distance apart inside of the field plot (Mouen Bedimo et al. 2007). Statistically, semivariance is related to the autocorrelation and is defined by the function $Y(h)=[(1 / 2) n(h)] \sum\left(z_{i}-z_{i+h}\right) 2$, where $Y(h)$, the semivariance for interval distance class $h$, is half the average of the sum of square differences between the percentage of disease for $n$ sample pairs of disease incidence rating areas, with lag interval $h ; z_{i}$ is the disease incidence percent in the disease areas at point $i$; and $z_{i+h}$ is the percentage measured for sample disease areas at point $i+h$. The data were fitted to the exponential, spherical, and Gaussian isotropic model variograms to analyze the multidirectional spatial dependence between disease incidence areas. All three models are described by their range, the nugget, and sill.

The range is the separation distance over which the samples are spatially dependent, the nugget $\left(\mathrm{C}_{0}\right)$ is the y-intercept of the model (essentially, the variance in disease incidence at zero lag, which may indicate errors in measurements or spatial dependence below the minimum measured distance), and the sill $\left(\mathrm{C}+\mathrm{C}_{0}\right)$ is the asymptote of the semivariance of the model. The maximum log-compositelikelihood (MLCL) value, the residual sum of squares, the $R^{2}$ coefficient, and the proportion of $\mathrm{C} /\left(\mathrm{C}_{0}+\mathrm{C}\right)$ are statistics that are often used to interpret the validity of the variogram models. The MLCL provides a measure of how well the model fits the variogram data, is fairly robust in regards to assumptions of distributions, and is computationally simple (Curriero and Lele 1999), providing advantages over similar methods, such as maximum likelihood and restricted maximum likelihood. The $R^{2}$ coefficient provides an alternative indication of how well the model fits the variogram data. The proportion of $\mathrm{C} /\left(\mathrm{C}_{0}+\mathrm{C}\right)$ provides a measure of the proportion of the sill that is explained by spatially structured variance $(\mathrm{C})$. The proportion of $\mathrm{C} /\left(\mathrm{C}_{0}+\mathrm{C}\right)$ will be 1 for a variogram with no nugget effect and 0 where there is no detectable spatial dependence at the range specified.

Relationship between disease incidence and log spore copy number. To determine whether observed disease incidence in the rating areas could be explained by observed sporetrap data, disease incidence ratings and the natural log of the 
P. effusa copy numbers for the Salinas 2013-14 and 2014-15 epidemics were averaged daily. Disease incidence ratings were plotted against the natural $\log$ of the $P$. effusa copy numbers at different weekly lags of disease incidence, allowing for comparison between disease incidence and past levels of log spore copy number. These time-lagged relationships were examined using linear regression analyses as a simple means to detect dependence in the data.

\section{RESULTS}

Spore trapping. Although $P$. effusa was detected in both Salinas 2013-14 and Salinas 2014-15 winters, P. effusa levels increased dramatically over the course of both winters (Fig. 1). P. effusa levels increased steadily throughout the Salinas 2013-14 winter and peaked as disease incidence levels began to rise. Detectable $P$. effusa DNA levels in the Salinas 2014-15 winter increased rapidly although, late in the winter, detection of $P$. effusa was intermittent but increasing (Fig. 1), especially after mid-January, when the disease in the field was detected (as it was in the 2013-14 winter). The predominant wind directions occurring at the site were bimodal, and came from the northwest and southeast in both the Salinas 2013-14 and 2014-15 winters (Fig. 2). The wind distribution affected the observations of $P$. effusa DNA detection in both years. Levels of $P$. effusa DNA were particularly higher in 2013-14 on the southern and eastern traps in mid-January onward (Supplementary Fig. S3), consistent with a northwest wind flow. In the Salinas 2014-15 winter, detection was not concentrated at the southern and eastern spore traps (Supplementary Fig. S4), although the northwest wind speeds were only slightly lower in the 2014-15 winter compared with the 2013-14 winter season (Fig. 2).

Spatial analyses of spore-trap data. In both the Soledad 2013 and Salinas 2013-14 epidemics, detectable levels of $P$. effusa DNA declined with increasing distance from the known disease outbreak (Fig. 3). Linear regression of the natural log of the copy number on the natural $\log$ of the distance accounted for relatively high proportions of the observed variance (Fig. 3). Linear models fitted to untransformed distance data were also significant but had lower $R^{2}$ values, suggesting that they explained less of the data than regressions using natural log-transformed distance data.

The AIC values from the resampled Salinas 2013-14 and Soledad epidemic datasets were compared using Welch's $t$ test (Fig. 4). Results from the $t$ test suggest that the AIC values of models fitted to log-transformed distances from both epidemic locations were significantly lower than those fitted to untransformed distances, corroborating the conclusion that the power-law provided a better explanation of the observed data than an exponential relationship.

Disease incidence rating. Downy mildew symptoms were observed on spinach leaves for both winter seasons in the Salinas 2013-14 and Salinas 2014-15 plots (Fig. 1). Discussions with local commercial growers suggest that the experimental field was the only local field with notable levels of disease. Although the symptoms tended to occur in clusters, the entire field was quickly colonized in both winter seasons (Fig. 1). Chlorotic symptoms on the leaves were often accompanied by sporulation, which most

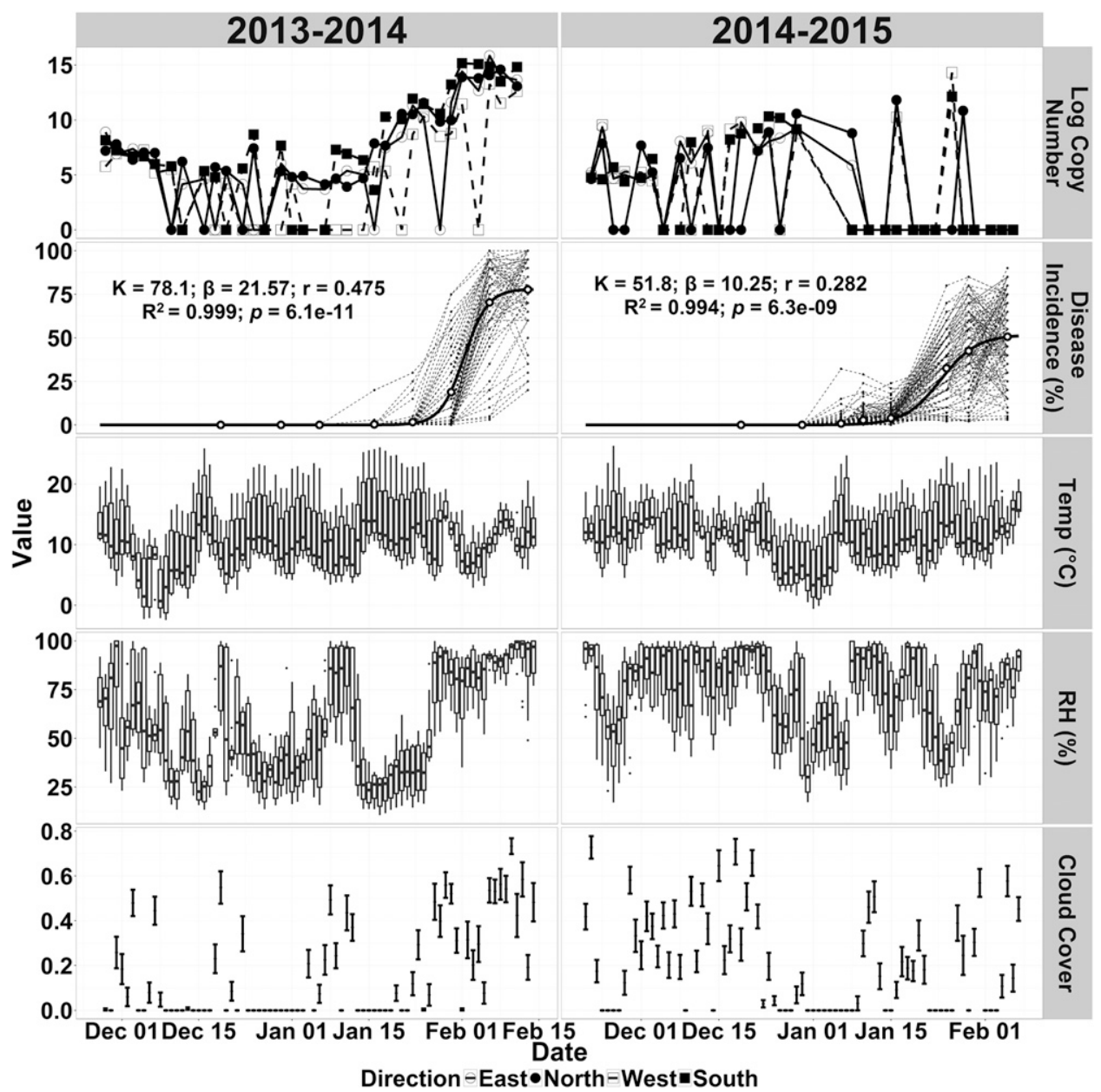

Fig. 1. Line plot of the natural log of Peronospora effusa DNA copy number from four different traps, and line plots of disease incidence (\%) from rated areas, temperature $\left({ }^{\circ} \mathrm{C}\right)$, relative humidity $(\%)$, and mean and standard error of cloud cover during the Salinas Valley epidemics in 2013-14 and 2014-15. Temperature, relative humidity, and cloud cover represent hourly data. Solid lines in disease incidence represent results of the fitted logistic growth model $Y=K /[1+\beta(-r t)]$ of the average spinach downy mildew disease incidence, represented by hollow white circles. Parameters for the logistic growth models are indicated within the disease incidence graphs. 


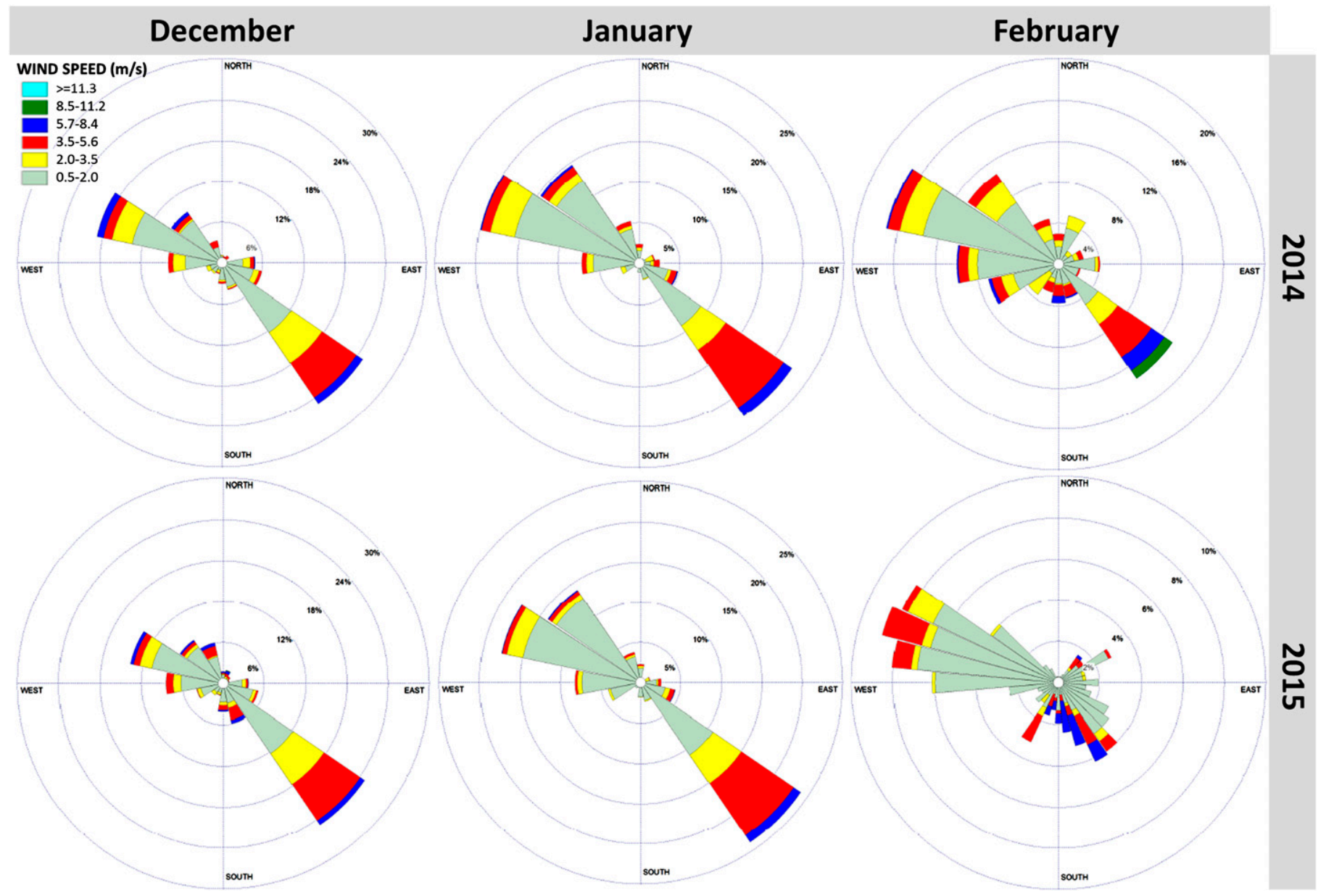

Fig. 2. Windroses illustrating wind direction and speed at the United States Department of Agriculture-Agricultural Research Service station in Salinas, CA from the Salinas 2013-14 and Salinas 2014-15 winter seasons.

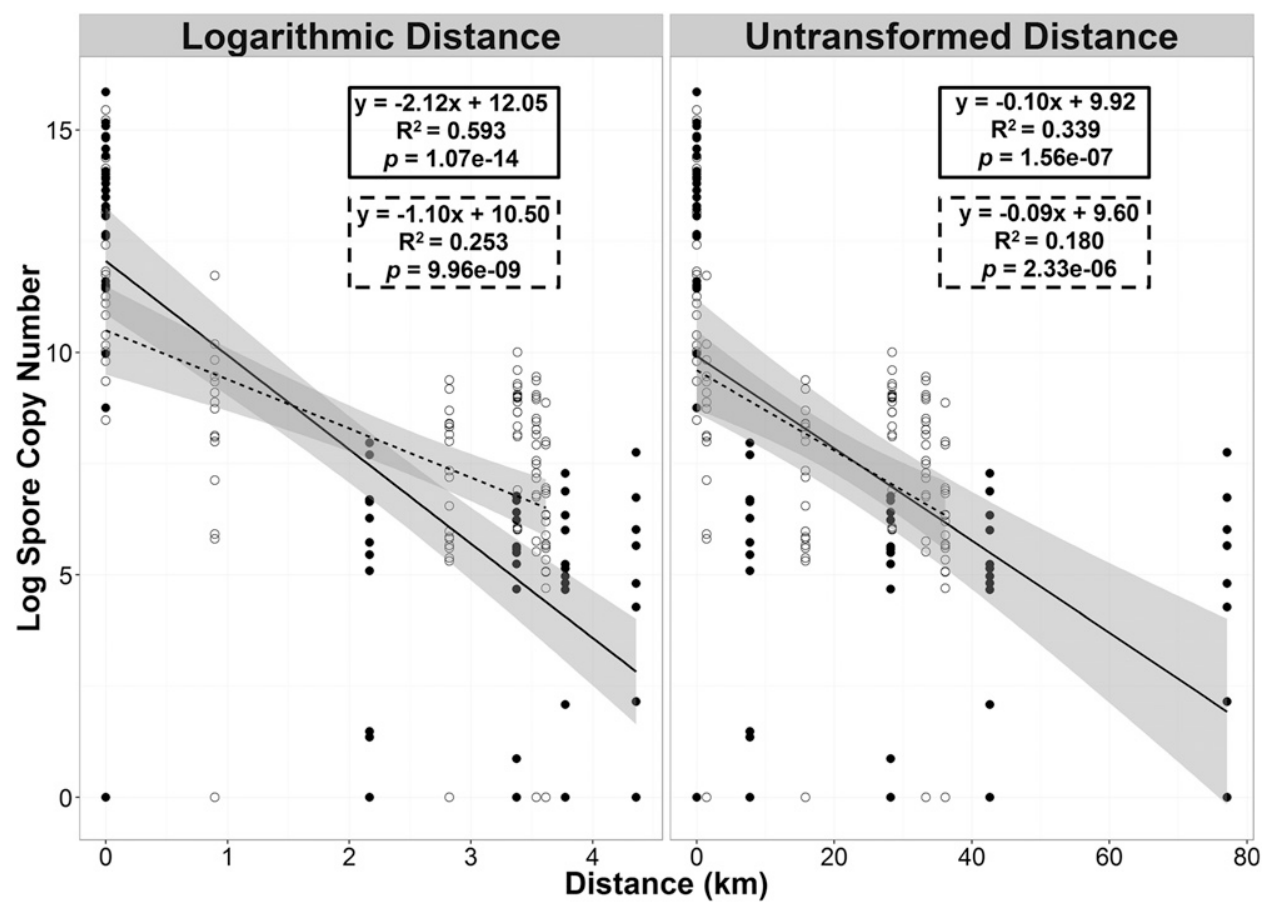

Fig. 3. Natural log of Peronospora effusa DNA copy number derived from quantitative polymerase chain reaction on spore-trap samples collected at an active spinach downy mildew epidemic site and from spore traps at more distant locations. Spore-trap data are plotted against both natural log and untransformed distance data. Hollow points and solid points represent epidemics in Soledad and Salinas, CA, respectively. Dashed and solid lines represent the lines of best fit for the Soledad and Salinas epidemics, respectively, and the gray area represents the 95\% confidence interval region. Summaries of the linear regression models are given in the inserted boxes; solid and dashed outlines represent regression output for the Salinas and Soledad epidemics, respectively. 
often occurred within the canopy of the spinach row. Different disease assessment areas throughout the field became infected at different times, although all rated areas had some diseased leaves by the final rating. As diseased leaves age, they succumb to secondary infections and senesce, with the result that disease incidence declined in several rating areas during the final rating periods in both years.

Temporal analysis of disease incidence data. The mean \pm standard error of the AUDPC values from the rated plots of the 2013-14 and 2014-15 epidemics were 910.1 \pm 40.3 and $684.6 \pm$ 22.8, respectively (Fig. 5). The result from the Welch's two-sample $t$ test suggest that the AUDPC from the 2 years were significantly different $(P<0.001)$ (Fig. 5).

Logistic models were fitted to describe the disease progression for both the Salinas 2013-14 and 2014-15 winter seasons (Fig. 1). This difference in overall disease incidence is corroborated by the rate parameter $(r)$ and the final carrying capacity $(K)$, which indicate a more rapid and severe epidemic in the Salinas 2013-14 winter (Fig. 1). The maximum daily rates of change in the estimated logistic curve were 9.23 and 3.64 in the Salinas 2013-14 and 2014-15 epidemics, respectively.

Spatial analysis of disease incidence data. Semivariograms were fit to disease incidence data from both the Salinas 2013-14 and 2014-15 winter seasons (Fig. 6). Most of the rating periods in

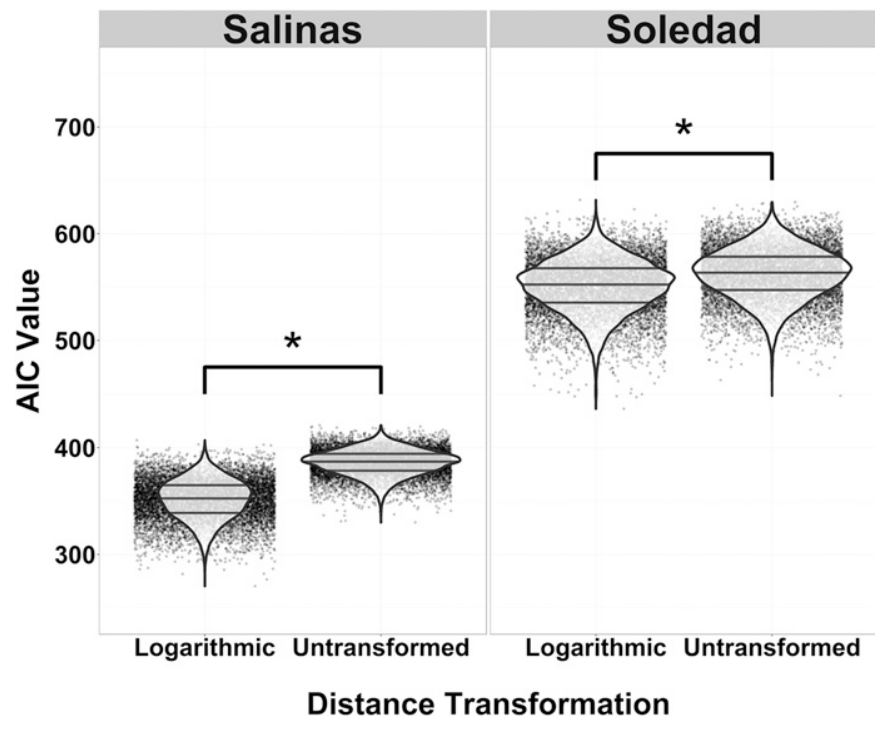

Fig. 4. Scatterplot and violin plot with quantiles of the Akaike information criterion (AIC) values for the linear regression of the natural log of the Peronospora effusa spore copy number and logarithmic or natural distance from 10,000 bootstrap resampled datasets from the Salinas 2013-14 and Soledad 2013 epidemics. Asterisks represent statistical significance $(P \leq 0.05)$.

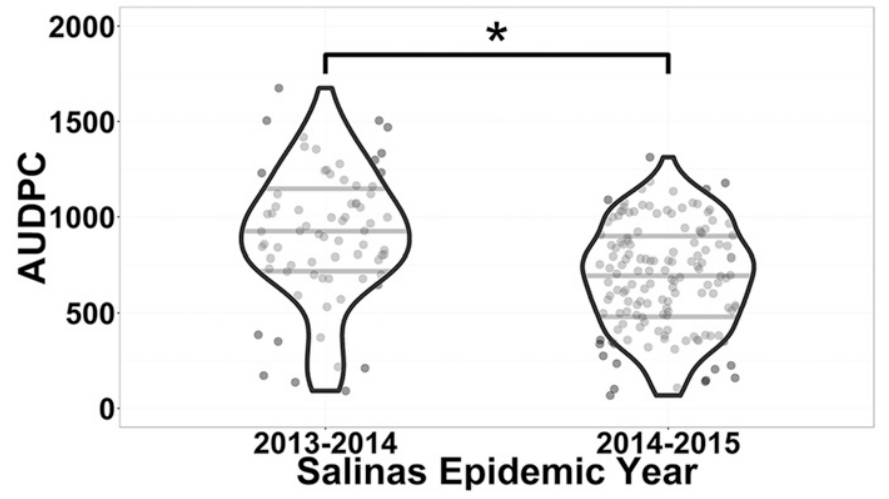

Fig. 5. Scatterplot and violin plot with quantiles of the area under the disease progress curve (AUDPC) values for rated areas in the 2013-14 and 2014-15 Salinas epidemics. Asterisks represent statistical significance $(P \leq 0.05)$. the Salinas 2013-14 winter and the first two rating periods of Salinas 2014-15 winter had no discernible spatial correlation (Table 1). Of the rating periods that had discernible spatial correlation, the average range of spatial correlation was $5.6 \mathrm{~m}$. Two of the rating periods were fit using the Gaussian model, four were fit using the exponential model, and one was fit using the spherical model.

Relationship between disease incidence and log spore copy number. Mean disease incidence of the field of susceptible spinach was positively correlated with the average of the natural log of spore copy number at 1 and 2-week lags but not significantly correlated with 0- and 3-week lags (Fig. 7). Results of the linear regression analyses from 1- and 2-week lags suggest that, for every 1 unit increase in the natural $\log$ of the P. effusa copy number, there is a 3 to $4 \%$ increase in the resulting disease incidence per rating areas (Fig. 4).

\section{DISCUSSION}

Spore trapping in the Salinas 2013-14 and 2014-15 winter seasons revealed detectable, low levels of $P$. effusa, even in the absence of disease in the adjacent susceptible field. With relatively few spinach plantings over the fall and winter months in the Salinas Valley, the source of this airborne inoculum remains unknown. The spores may have come from infected noncommercial spinach being grown in local gardens or from LDD from outside the region. In other spore-trapping studies of aerially dispersed obligate biotrophic pathogens, detection was minimal during nonhost periods (Falacy et al. 2007).

Although $P$. effusa was detected in both the Salinas 2013-14 and 2014-15 winter seasons, there were marked differences in the overall spatial and temporal patterns of detection. Levels of $P$. effusa DNA detection at the four cardinal traps were different in the 2013-14 winter season versus the 2014-15 winter season. Levels of P. effusa DNA were higher in 2013-14 on the southern and eastern

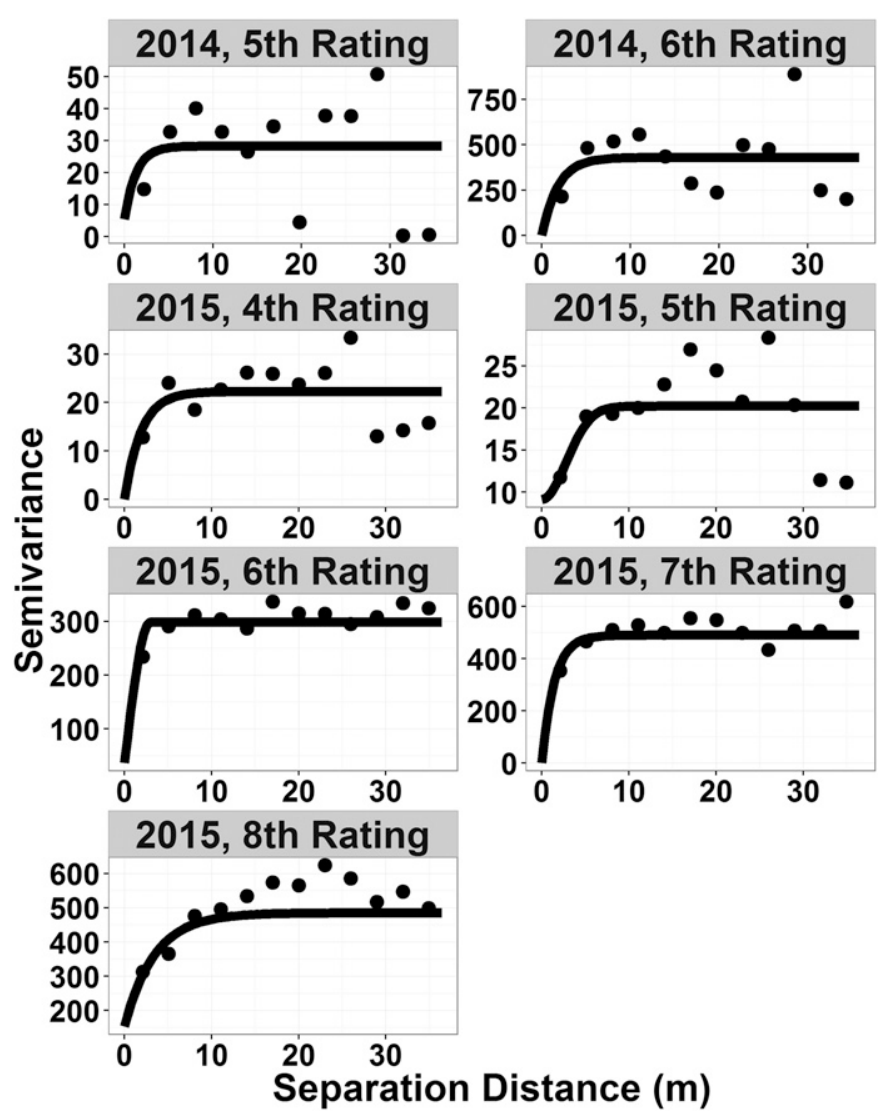

Fig. 6. Semivariograms from different spinach downy mildew disease incidence rating periods during the Salinas Valley epidemics in 2013-14 and 2014-15. 
traps in mid-January onward, mirroring the increase in disease incidence and reflecting the northwest wind flow during periods of spore release. During the 2014-15 winter season, levels of $P$. effusa DNA were higher in the northern, southern, and western traps. Over the course of the Salinas 2013-14 winter, there was a relatively low but consistent proportion of $P$. effusa detected in late November and December. Although the detection seemed to level off for much of late December, overall detection began to increase again in January as the local susceptible field was infected. In the Salinas 2014-15 winter, $P$. effusa levels increased steadily through mid-January and had sporadic bursts through late January and early February, mirroring the increase in disease incidence. This intermittent sporulation may have been due to unsuitable weather factors for sporulation and dispersal. It is also possible that the observed increase in disease symptoms such as chlorosis and decline of leaves may not have been accompanied by proportional amounts of increased sporulation (Aegerter et al. 2003).

Early studies in aerobiology proposed that many plant-pathogenic fungal and oomycete spores are exponentially distributed, allowing for LDD (Aylor 2003; Fitt et al. 1987). LDD on continental scales has been described for several downy mildew pathogens, notably P. tabacina and Pseudoperonospora cubensis (LaMondia and Aylor 2001; Lucas 1980; Ojiambo and Holmes 2011; Savory et al. 2011). These two species take advantage of meteorological conditions that carry spores from the southeastern United States up through eastern and central Canada, in what is referred to as the "Peronospora pathway" (Aylor 2003). The pathogens overwinter in the warmer southern regions, then recolonize northern regions that have experienced extirpation. It is difficult to assess whether Peronospora effusa disperses from the Salinas Valley to the Yuma and Imperial Valleys through an analogous pathway. The Peronospora pathway that links the southeastern and north-central United States is typically completed by multiple regional-scale dispersal jumps, rather than a single, continental-wide dispersal event. The Peronospora pathway is possible in the eastern United States, where cucurbit and tobacco hosts are widespread. Spinach, in contrast, is rarely grown on a significant scale anywhere in between the widely separated Salinas Valley and Imperial and Yuma Valleys in the western United States.

Understanding how aerial-dispersed spores are distributed across space has improved regional disease management practices in other pathosystems (Skelsey et al. 2009). We monitored P. effusa levels at two outbreaks in Salinas and Soledad as well as sites throughout the Salinas Valley. Overall, $P$. effusa levels immediately adjacent to the outbreaks were orders of magnitude higher than those further from the epidemics. However, while detection levels decreased with distance from the outbreak, inoculum detection was fairly uniform at long distances. This "fat tail" effect is typical of power-law distributions (Clauset et al. 2009). Making the empirical distinction between power-law and exponential distributions is notoriously difficult because of the challenge in collecting sufficient numbers of observations at large distances from the source. In the present study, utilizing linear regression to assess model suitability, the spatial

TABLE 1. Parameters from the semivariograms describing spatial patterns of spinach downy mildew disease incidence at the Salinas Valley site during epidemics in 2013-14 and 2014-15

\begin{tabular}{lcccccccc}
\hline Year & Rating period & Range & Sill & C/Co+C & MLCL $^{\mathrm{a}}$ & RSS $^{\mathrm{b}}$ & $R^{2}$ & Model $^{\mathrm{c}}$ \\
\hline $2013-14$ & $1,2,3,4$ & $\ldots$ & $\ldots$ & 0.00 & $\ldots$ & $\ldots$ & $\ldots$ & Pure nugget effect \\
$2013-14$ & 5 & 3.95 & 28.3 & 0.81 & $-15,794.07$ & $3,025.8$ & 0.036 & Gaussian \\
$2013-14$ & 6 & 5.40 & 429.2 & 1.00 & $-22,734.5$ & $393,644.6$ & 0.086 & Exponential \\
$2013-14$ & 7,8 & $\ldots$ & $\ldots$ & 0.00 & $\ldots$ & $\ldots$ & $\ldots$ & Pure nugget effect \\
$2014-15$ & $1,2,3$ & $\ldots$ & $\ldots$ & 0.00 & $\ldots$ & $\ldots$ & Pure nugget effect \\
$2014-15$ & 4 & 5.75 & 22.3 & 1.00 & $-61,077.7$ & 392.2 & 0.146 & Exponential \\
$2014-15$ & 5 & 6.79 & 20.2 & 0.17 & $-60,076.8$ & 299.6 & 0.183 & Gaussian \\
$2014-15$ & 6 & 4.38 & 298.1 & 0.52 & $-87,851.2$ & $4,804.2$ & 0.406 & Spherical \\
$2014-15$ & 7 & 489.9 & 1.00 & $-92,951.1$ & $30,625.3$ & 0.356 & Exponential \\
$2014-15$ & 8 & 10.39 & 484.4 & 0.54 & $-92,782.2$ & $56,451.7$ & 0.368 & Exponential \\
\hline
\end{tabular}

a Maximum log-composite-likelihood.

${ }^{b}$ Residual sum of squares.

c Spatial correlation models were calculated as $R(h)=e^{-h}, R(h)=e^{-h 2}$, and $R(h)=\left(1-1.5 h+0.5 h^{3}\right) 1_{[0,1]}(h)$ for the exponential, Gaussian, and spherical models, respectively (Padoan and Bevilacqua 2015).

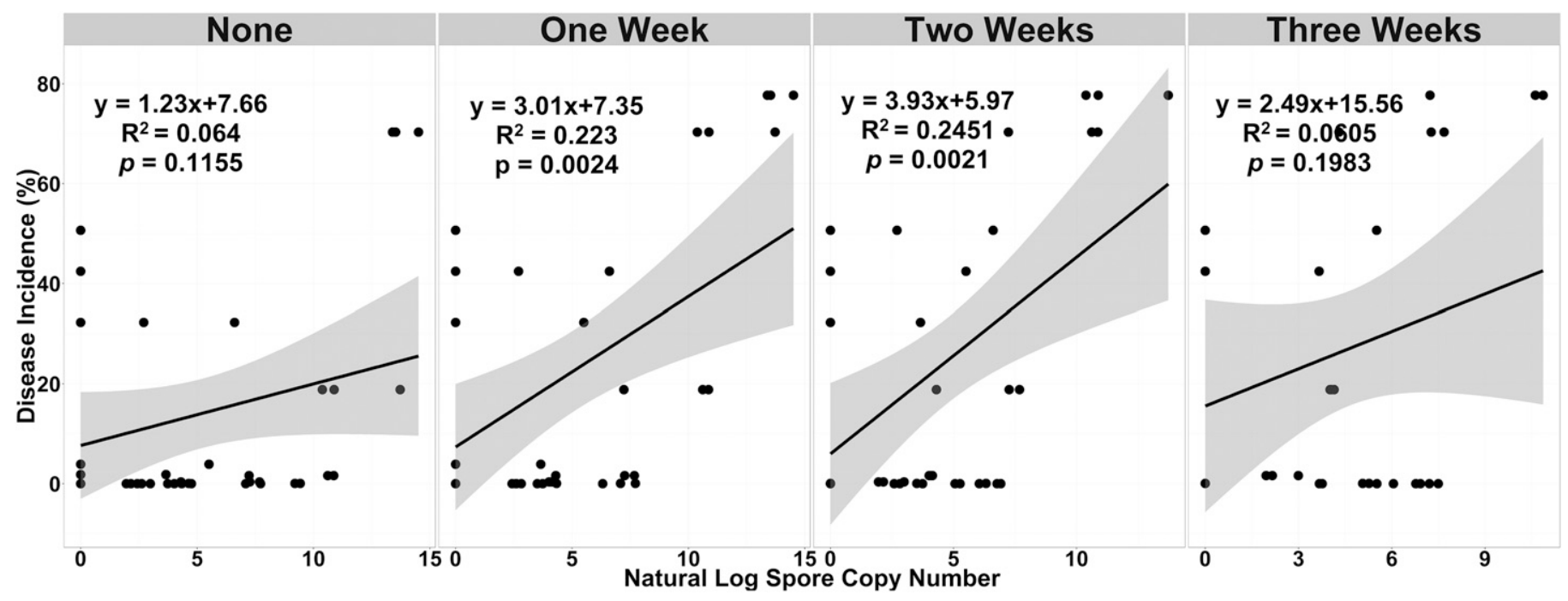

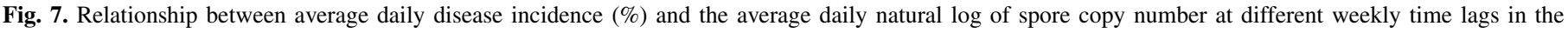
Salinas 2013-14 and 2014-15 epidemics. 
distribution of spores captured during an active epidemic most closely fit a power-law distribution but could also fit with an exponential distribution. Fitt et al. (1987) found that the distribution of $P$. schachtii-infected sugar beet plants fit the exponential distribution slightly better than the power-law. The authors also analyzed data from many different pathogens, and noted that pathogens that dispersed using smaller spores $(<10 \mu \mathrm{m}$ in linear dimension) tended to fit a power-law distribution better than those that produced larger spores, such as those of $P$. effusa, whose sporangia are typically 21 to $33 \mu \mathrm{m}$ long (Choi et al. 2007). Overall, the weight of evidence from our observations on $P$. effusa in the Salinas Valley is that airborne inoculum is mostly deposited close to its source but that a detectable proportion is present in the air at concentrations that are independent of distance from source, resulting in a fat-tailed distribution for the relationship between inoculum and source.

Fields planted with a susceptible spinach variety adjacent to the spore traps in both the Salinas 2013-14 and 2014-15 winters were naturally infected with downy mildew. Regular scouting and monitoring of the field for disease incidence revealed increasing disease as the epidemic progressed. Logistic curve-fitting analysis suggests that both epidemics followed a logistic curve that is typical of a polycyclic disease (Madden et al. 2007). The maximum estimated rate of disease increase was $9.23 \%$ per day in 2014 versus $3.64 \%$ in 2015 . These findings seem to qualitatively match previously described temporal patterns of outbreaks of spinach downy mildew in The Netherlands (Frinking and Linders 1986), although the rate of disease increase in our study appears to be higher. This might be due to differences in weather patterns or modern agronomic practices such as increased planting density and wider beds. It may also simply be due to differences in disease scouting and rating techniques, because our study monitored the incidence of infected leaves and their study focused on disease severity as area of leaf affected. Toward the end of the rating period, disease declined in several rating areas. This could be due to infected plant tissue becoming senescent, while new leaflets developed induced resistance to infection (Vallad and Goodman 2004).

Understanding spatial aspects of plant disease aggregation can help in disease prediction and control (Mouen Bedimo et al. 2007; Stein et al. 1994). Understanding how disease aggregation occurs can help with roguing and sanitation practices, as well as direct sampling strategies. Plant diseases typically aggregate as disease foci: localized clusters of diseased plants (Zadoks and van den Bosch 1994). This clustering occurs on different spatial scales, with smaller foci aggregating into larger foci, possibly even expanding to regional-scale epidemics. We used semivariograms to assess the area of spatial dependence in our two Salinas epidemics. We found that disease was spatially dependent within an average radius of $5.6 \mathrm{~m}$. This corresponds approximately to the width of three beds, a relatively small scale in terms of the total spinach acreage in a typical field. This range corresponds closely to the range of other downy mildew pathogens, including Pseudoperonospora humuli and Hyaloperonospora brassicae, which had average ranges of approximately 7.5 and $5 \mathrm{~m}$, respectively (Johnson et al. 1991; Stein et al. 1994). The similarity in the range might be due to similar dispersal mechanisms and infection capabilities. The results indicated that scouting to estimate disease incidence for spinach downy mildew should be based on samples separated by distances of $5.6 \mathrm{~m}$ to obtain individual samples that are statistically independent. The distinction between spatial distributions of diseased plants and the distribution of spores (see above) is critical, because the viability of wind-deposited propagules often declines over long distances (Skelsey et al. 2009). Because of this decline in viability, spatial aggregation and distribution of diseased plants can be very different from the distribution of propagules.

In other spore-trapping studies, spore detection rates are often tightly linked with disease incidence and severity in nearby crops
(Carisse et al. 2008a,b; Granke et al. 2014). Researchers have used this link between spore detection and disease increase to improve disease prediction and timing of protective fungicides (Thiessen et al. 2016). The results of our linear regression suggest that there is a lagged correlation between spore copy number detected and increase in disease incidence, and that every log unit increase in spore copy number results in approximately 3 to $4 \%$ higher disease incidence in 1 to 2 weeks, respectively. However, the results of our LDD study suggest that spore levels measured outside of epidemics are fairly uniform, even at great distances. This background level of spores could present challenges when implementing spore-trapping methods for spinach downy mildew disease prediction.

This study highlights some of the complexities and difficulties in using spore traps as part of a decision support system for spinach downy mildew. However, at the Salinas Valley plot in 2013-14 and 2014-15, the increase in disease incidence was reflected in the increasing levels of Peronospora. effusa DNA detectable in spore traps, providing the potential opportunity to exploit trap- and DNAbased detection at the field or ranch level for an early warning system on that scale. On a larger scale, LDD events could obscure the source of detected levels of $P$. effusa by creating a uniform blanket of spores across the region. Epidemics occur at different speeds and with different spatial aggregations and scales. Although these findings highlight some of the uncertainty in the spinach downy mildew system, they also highlight common features with other disease systems. Predicting disease outbreaks and finding practical control methods remain as critically important goals for protecting susceptible spinach crops.

\section{ACKNOWLEDGMENTS}

We thank the California Leafy Greens Research Program and the California Department of Agriculture Specialty Crop Block Grant Program (number SCB14043) for funding this research, W. Mahaffee (United States Department of Agriculture-Agricultural Research Service [USDA-ARS], Corvallis, OR) for providing some spore-trap materials and advice, L. Ochoa (USDA-ARS, Salinas, CA) and R. Pena (Hartnell College, Salinas, CA) for collecting spore-trap samples, S. Benzen for maintaining the Salinas USDA-ARS spinach plots, L. Montenegro and R. Gearheart for weather data programming and support, K. Arnold and C. Gigot for helpful comments on data analysis, and two anonymous reviewers and C.-L. Xiao for their helpful comments and suggestions.

\section{LITERATURE CITED}

Aegerter, B. J., Nuñez, J. J., and Davis, R. M. 2003. Environmental factors affecting rose downy mildew and development of a forecasting model for a nursery production system. Plant Dis. 87:732-738.

Aylor, D. E. 2003. Spread of plant disease on a continental scale: Role of aerial dispersal of pathogens. Ecology 84:1989-1997.

Brown, J. K., and Hovmøller, M. S. 2002. Aerial dispersal of pathogens on the global and continental scales and its impact on plant disease. Science 297: 537-541.

Byford, W. J. 1967. Host specialization of Peronospora farinosa on Beta, Spinacia and Chenopodium. Trans. Br. Mycol. Soc. 50:603-607.

Carisse, O., McRoberts, N., and Brodeur, L. 2008a. Comparison of monitoring- and weather-based risk indicators of Botrytis leaf blight of onion and determination of action thresholds. Can. J. Plant Pathol. 30:442-456.

Carisse, O., Savary, S., and Willocquet, L. 2008b. Spatiotemporal relationships between disease development and airborne inoculum in unmanaged and managed Botrytis leaf blight epidemics. Phytopathology 98:38-44.

Choi, Y. J., Hong, S. B., and Shin, H. D. 2007. Re-consideration of Peronospora farinosa infecting Spinacia oleracea as distinct species, Peronospora effusa. Mycol. Res. 111:381-391.

Choi, Y. J., Klosterman, S. J., Kummer, V., Voglmayr, H., Shin, H. D., and Thines, M. 2015. Multi-locus tree and species tree approaches toward resolving a complex clade of downy mildews (Straminipila, Oomycota), including pathogens of beet and spinach. Mol. Phylogenet. Evol. 86:24-34.

Clauset, A., Shalizi, C. R., and Newman, M. E. 2009. Power-law distributions in empirical data. SIAM Rev. 51:661-703.

Correll, J. C., Bluhm, B. H., Feng, C., Lamour, K., Du Toit, L. J., and Koike, S. T. 2011. Spinach: Better management of downy mildew and white rust through genomics. Eur. J. Plant Pathol. 129:193-205. 
Curriero, F. C., and Lele, S. 1999. A composite likelihood approach to semivariogram estimation. J Agric. Biol. Environ. Stat. 4:9-28.

de Mendiburu, F. 2015. agricolae: Statistical Procedures for Agricultural Research. R package version 1.2-3. Online publication. https://cran.r-project. org/web/packages/agricolae/index.html

Falacy, J. S., Grove, G. G., Mahaffee, W. F., Galloway, H., Glawe, D. A., Larsen, R. C., and Vandemark, G. J. 2007. Detection of Erysiphe necator in air samples using the polymerase chain reaction and species-specific primers. Phytopathology 97:1290-1297.

Feng, C., Correll, J. C., Kammeijer, K. E., and Koike, S. T. 2014. Identification of new races and deviating strains of the spinach downy mildew pathogen Peronospora farinosa $\mathrm{f}$. sp. spinaciae. Plant Dis. 98:145-152.

Fitt, B. D., Todd, A. D., McCartney, H. A., and Macdonald, O. C. 1987. Spore dispersal and plant disease gradients; a comparison between two empirical models. J. Phytopathol. 118:227-242.

Forster, M., and Sober, E. 1994. How to tell when simpler, more unified, or less ad hoc theories will provide more accurate predictions. Br. J. Philos. Sci. 45:1-35.

Fox, A. D. 2011. MtnRT White Paper: Summary of the MtnRT System. Providing weather inputs for plant disease models. Online publication. www.foxweather2.com

Frinking, H. D., and Linders, E. G. A. 1986. A comparison of two pathosystems: Downy mildew on Spinacia oleracea and on Chenopodium album. Neth. J. Plant Pathol. 92:97-106.

Frinking, H. D., and van der Stoel, M. C. 1987. Production of conidia by Peronospora farinosa f. sp. spinaciae. Neth. J. Plant Pathol. 93:189-194.

Gadoury, D. M., Cadle-Davidson, L., Wilcox, W. F., Dry, I. B., Seem, R. C., and Milgroom, M. G. 2012. Grapevine powdery mildew (Erysiphe necator): A fascinating system for the study of the biology, ecology and epidemiology of an obligate biotroph. Mol. Plant Pathol. 13:1-16.

Granke, L. L., Morrice, J. J., and Hausbeck, M. K. 2014. Relationships between airborne Pseudoperonospora cubensis sporangia, environmental conditions, and cucumber downy mildew severity. Plant Dis. 98:674-681.

Hijmans, R. J. 2016. geosphere: Spherical Trigonometry. R package version 1.5-5. Online publication. https://cran.r-project.org/web/packages/geosphere/ index.html

Johnson, D. A., Alldredge, J. R., Allen, J. R., and Allwine, R. 1991. Spatial pattern of downy mildew in hop yards during severe and mild disease epidemics. Phytopathology 81:1369-1374.

Kellogg, C. A., and Griffin, D. W. 2006. Aerobiology and the global transport of desert dust. Trends Ecol. Evol. 21:638-644.

Klosterman, S. J., Anchieta, A., McRoberts, N., Koike, S. T., Subbarao, K. V., Voglmayr, H., Choi, Y., Thines, M., and Martin, F. N. 2014. Coupling spore traps and quantitative PCR assays for detection of the downy mildew pathogens of spinach (Peronospora effusa) and beet (P. schachtii). Phytopathology 104:1349-1359.

Koike, S. T., Cahn, M., Cantwell, M., Fennimore, S., LeStrange, M., Natwick, E., Smith, R. F., and Takele, E. 2011. Spinach Production in California. Univ. Calif. Agric. Nat. Resour. Publ. 7212.

Kunjeti, S. G., Anchieta, A., Subbarao, K. V., Koike, S. T., and Klosterman, S. J. 2016. Plasmolysis and vital staining reveal viable oospores of Peronospora effusa in spinach seed lots. Plant Dis. 100:59-65.

LaMondia, J. A., and Aylor, D. E. 2001. Epidemiology and management of a periodically introduced pathogen. Biol. Invasions 3:273-282.

Lucas, G. B. 1980. The war against blue mold. Science 210:147-153.

Madden, L. V., Hughes, G., and van den Bosch, F. 2007. The Study of Plant Disease Epidemics. The American Phytopathological Society, St. Paul, MN.

McDonald, B. A., and Linde, C. 2002. Pathogen population genetics, evolutionary potential, and durable resistance. Annu. Rev. Phytopathol. 40: 349-379.
McRoberts, N., Hall, C., Madden, L. V., and Hughes, G. 2011. Perceptions of disease risk: From social construction of subjective judgments to rational decision making. Phytopathology 101:654-665.

Mesinger, F., DiMego, G., Kalnay, E., Mitchell, K., Shafran, P. C., Ebisuzaki, W., Jovic, D., Woollen, J., Rogers, E., Berbery, E. H., Ek, M. B., Fan, Y., Grumbine, R., Higgins, W., Li, H., Lin, Y., Manikin, G., Parrish, D., and Shi, W. 2006. North American Regional Reanalysis: A long-term, consistent, high-resolution climate dataset for the North American domain, as a major improvement upon the earlier global reanalysis datasets in both resolution and accuracy. Bull. Am. Meteorol. Soc. 87:343-360.

Montarry, J., Corbière, R., and Andrivon, D. 2007. Is there a trade-off between aggressiveness and overwinter survival in Phytophthora infestans? Funct. Ecol. 21:603-610.

Mouen Bedimo, J. A., Bieysse, D., Cilas, C., and Nottéghem, J. L. 2007. Spatio-temporal dynamics of arabica coffee berry disease caused by Colletotrichum kahawae on a plot scale. Plant Dis. 91:1229-1236.

Ojiambo, P. S., and Holmes, G. J. 2011. Spatiotemporal spread of cucurbit downy mildew in the eastern United States. Phytopathology 101:451-461.

Padoan, S. A., and Bevilacqua, M. 2015. Analysis of random fields using CompRandFld. J. Stat. Softw. 63:1-27. https://www.jstatsoft.org/v63/i09/

R Core Team. 2016. R: A Language and Environment for Statistical Computing. R Foundation for Statistical Computing, Vienna. Online publication. https://www.R-project.org/

Savory, E. A., Granke, L. L., Quesada-Ocampo, L. M., Varbanova, M., Hausbeck, M. K., and Day, B. 2011. The cucurbit downy mildew pathogen Pseudoperonospora cubensis. Mol. Plant Pathol. 12:217-226.

Skelsey, P., Kessel, G. J. T., Holtslag, A. A. M., Moene, A. F., and Van Der Werf, W. 2009. Regional spore dispersal as a factor in disease risk warnings for potato late blight: A proof of concept. Agric. For. Meteorol. 149:419-430.

Spanu, P. D. 2012. The genomics of obligate (and nonobligate) biotrophs. Annu. Rev. Phytopathol. 50:91-109.

Sparks, A. H., Esker, P. D., Antony, G., Campbell, L., Frank, E. E., Huebel, L., Rouse, M. N., Van Allen, B., and Garrett, K. A. 2008. Ecology and epidemiology in R: Spatial analysis. Online publication. Plant Health Instruct. doi:10.1094/PHI-A-2008-0129-03

Stein, A., Kocks, C. G., Zadoks, J. C., Frinking, H. D., Ruissen, M. A., and Myers, D. E. 1994. A geostatistical analysis of the spatio-temporal development of downy mildew epidemics in cabbage. Phytopathology 84: 1227-1239.

Thiessen, L. D., Keune, J. A., Neill, T. M., Turechek, W. W., Grove, G. G., and Mahaffee, W. F. 2016. Development of a grower-conducted inoculum detection assay for management of grape powdery mildew. Plant Pathol. 65: 238-249.

Thines, M., and Choi, Y.-J. 2016. Evolution, diversity, and taxonomy of the Peronosporaceae, with focus on the genus Peronospora. Phytopathology 106:6-18.

USDA-NASS. 2015. Spinach production data. USDA National Agricultural Statistics Service. https:/quickstats.nass.usda.gov/

Vallad, G. E., and Goodman, R. M. 2004. Systemic acquired resistance and induced systemic resistance in conventional agriculture. Crop Sci. 44: 1920-1934.

van den Bosch, F., Frinking, H. D., Metz, J. A. J., and Zadoks, J. C. 1988. Focus expansion in plant disease. III: Two experimental examples. Phytopathology 78:919-925.

Wu, B. M., Van Bruggen, A. H. C., Subbarao, K. V., and Pennings, G. G. H. 2001. Spatial analysis of lettuce downy mildew using geostatistics and geographic information systems. Phytopathology 91:134-142.

Zadoks, J. C., and van den Bosch, F. 1994. On the spread of plant disease: A theory on foci. Annu. Rev. Phytopathol. 32:503-521. 